\title{
We can Diagnose it if we Consider it. Diagnostic Pitfall for Placenta: Placental Mesenchymal Dysplasia
}

\author{
Havva Serap TORU', Esra ÇOBANKENT AYTEKIN ${ }^{1}$, Cem Yaşar SANHAL ${ }^{2}$, Sezin YAKUT², Zafer ÇETIN", \\ İbrahim İnanç MENDILCIOĞLU², Hadice Elif PEŞTERELi' ${ }^{1}$
}

Department of ${ }^{1}$ Pathology, ${ }^{2}$ Obstetrics and Gynecology and ${ }^{3}$ Medical Biology and Genetics, Akdeniz University, School of Medicine, ANTALYA, TURKEY, ${ }^{4}$ Department of Medical Biology, SANKO University School of Medicine, GAZIANTEP, TURKEY

\begin{abstract}
Placental mesenchymal dysplasia is an increasingly recognizable abnormality. Early cases have been confused with partial hydatidiform mole. Placental mesenchymal dysplasia is probably under-diagnosed because of being an unfamiliar clinical entity and also mistaken for gestational trophoblastic disease due to the similar sonographic findings of two entities. In this report, we describe the clinical, gross, and histopathological findings of placental mesenchymal dysplasia in two cases. The 33-week-preterm baby of a 26-year-old woman with cardiovascular disease and 342 gram placenta and the 19-week fetus with trisomy 21 of a 40 year-old woman were terminated. Macroscopically thick-walled vessels and microscopically hydropic villous with peripherally localized thick-walled vessels without trophoblastic cell proliferation were observed in both cases. These two cases represent a rare placental anomaly that is benign but it is challenging to distinguish placental mesenchymal dysplasia from an incomplete mole. Placental mesenchymal dysplasia should be included in the differential diagnosis of sonographic findings that show a normal appearing fetus and a placenta with cystic lesions. Placental mesenchymal dysplasia is associated with pregnancy-related hypertension. In conclusion, the most important point is "you can diagnose it if you consider it".
\end{abstract}

Key Words: Placental mesenchymal dysplasia, Molar pregnancy, Diagnostic errors

\section{INTRODUCTION}

Placental mesenchymal dysplasia (PMD) was first recognized by Takayama et al. as a distinct pathologic entity of the placenta (1). Other reports of unusual placentas with vascular abnormalities were published in 1980s and 1990s; finally Moscoso et al recognized the uniqueness of this order in 1991 and described it as a placental vascular anomaly with diffuse stem villous hyperplasia (2). PMD is an increasingly recognizable, rare placental vascular abnormality which is characterized by aneurysmal dilatation on the fetal surface of the placenta, with dilated stem cell villi (3). In contrast to molar pregnancies, trophoblastic proliferation is absent (4). Clinically and pathologically, PMD should be differentiated from complete mole, spontaneous abortion with hydropic changes, as well as confined placental mosaicism (5). Early cases of PMD have been confused with partial hydatidiform mole (6-10). PMD is probably under-diagnosed as it is an unfamiliar clinical entity and also mistaken for gestational trophoblastic disease because of similar sonographic findings of the two entities (11). The differential diagnosis is important as PMD is usually compatible with a karyotypically and morphologically normal fetus and a good maternal-fetal outcome (12).

(Turk Patoloji Derg 2018, 34:100-103)

Received : 30.06 .2014 Accepted : 02.10.2014
Data on PMD is limited to affected pregnancies because of the disorder's relatively recent recognition (13). The aim of this paper was to emphasize the recognition and diagnosis of this new entity.

We describe the clinical, gross and histopathological findings of PMD in two cases in this report.

\section{CASE REPORTS}

Case 1: A 26-year-old gravida 5, para 1 woman in her 32nd week of gestation, was referred to our perinatology unit from the cardiology department for intractable maternal tachycardia and the need to give birth. Her personal and family history was unremarkable, except having 2 intrauterine demises and an atrial-mitral valve replacement operation. In the present pregnancy, she had used warfarin from the first trimester, and had no history of fever (with or without rash) or ionizing radiation exposure. First trimester screening for aneuploidy had revealed a risk of 1:780 for Down syndrome. Her routine pregnancy follow-up was otherwise eventless. Cesarean section was performed and a healthy 2550 gram baby was delivered. The baby and mother were discharged in good condition 2 weeks later. Pathology examination showed an enlarged placenta weighing 487

Correspondence: Havva Serap TORU

Akdeniz Üniversitesi Tip Fakültesi Hastanesi,

Patoloji Anabilim Dalı, ANTALYA, TURKEY

E-mail: serap_toru@yahoo.com Phone: +90 2422496000 
gram. Macroscopically, the placental disc had prominent thick, circoid vessels and a white nodule (Figure 1).

Case 2: A 40-year-old gravida 2, para 1 woman in her 18th week of gestation, was referred to Akdeniz University Gynecology and Obstetrics Department, with a nuchal translucency measurement of $2.29 \mathrm{~mm}$ and combined risk of $>1 / 5$ for Down's syndrome detected in the first trimester screening test for fetal aneuploidy. Her personal and family histories were unremarkable. Her previous pregnancy was uneventful and the child was healthy. Her non-consanguineous husband was 45 years old.

An amniocentesis was performed the same day to analyze the fetal karyotype. Trisomy 21 was revealed two weeks later. The parents chose pregnancy termination after receiving

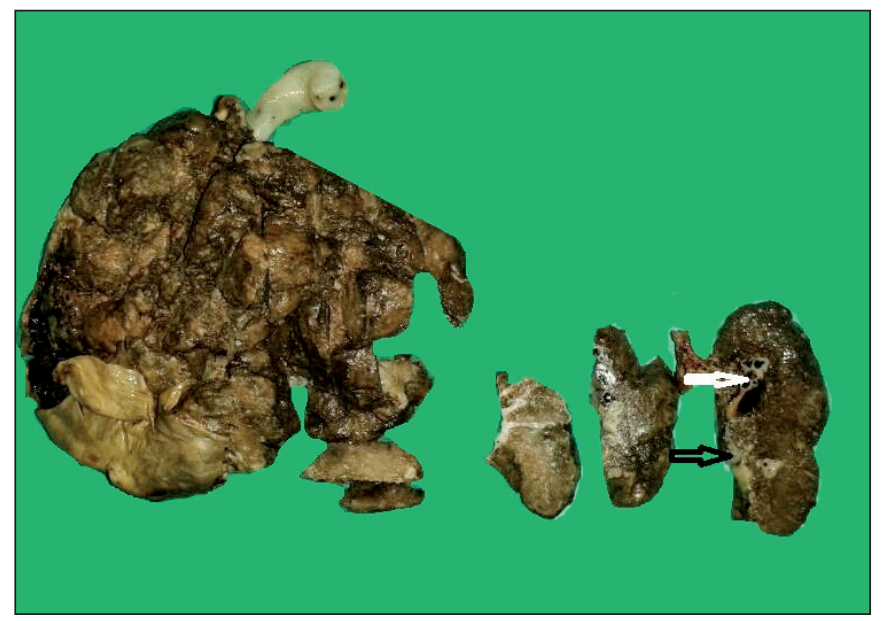

Figure 1: Placenta with prominent thick vessels (white arrow) and white nodule (black arrow).

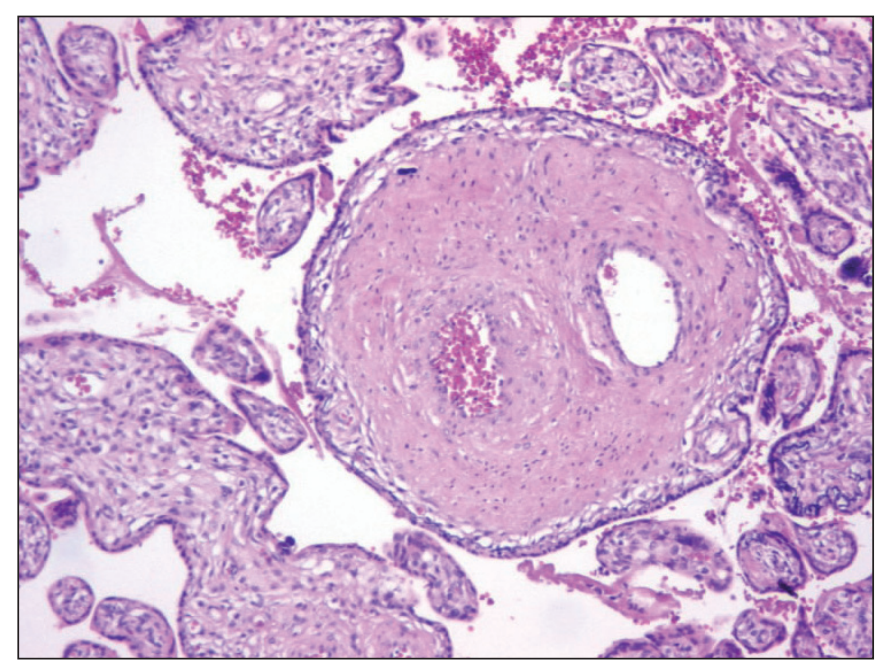

Figure 3: Light microscopy of Case 1 (H\&E; x20). counseling about Down's syndrome. The karyotype was trisomy 21 and macroscopically the 288 gram placenta had thick-walled vessels on the placental disc.

Microscopically variable villous maturation was present, ranging from mature with increased syncytial knotting to enlarged stem villi in both cases. The abnormal stem villi were large and edematous and contained peripherally localized, prominent thick-walled vessels of which some were obstructed (Figure 2,3). Trophoblastic cell proliferation and stromal inclusions were not observed. Evidence of villous edema was seen in some of the villi cisternae. These cisternae were negative for CD34 and D240 on immunohistochemical staining (Figure 4, 5). These findings were consistent with PMD.

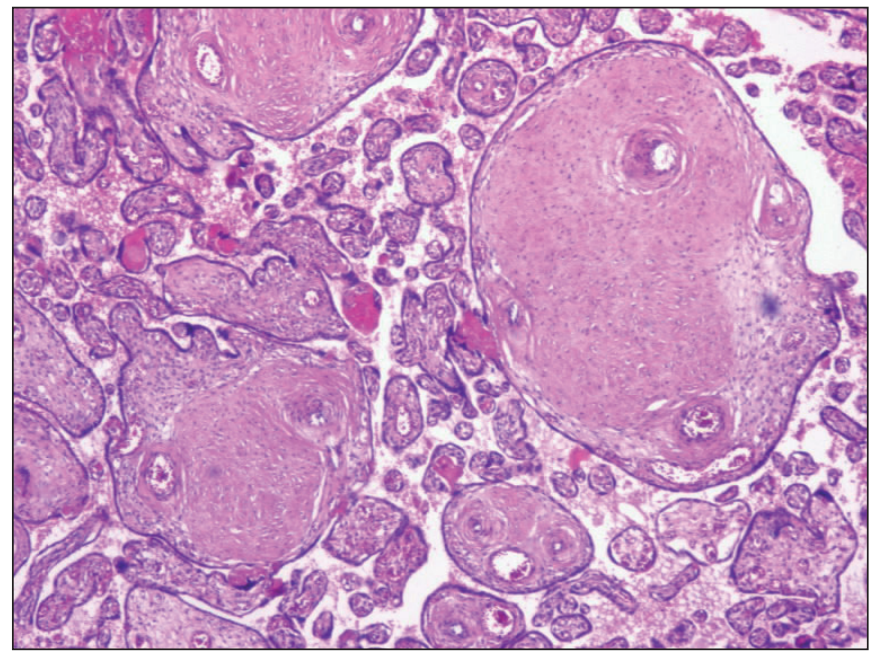

Figure 2: Light microscopy of Case 1 (H\&E; x10).

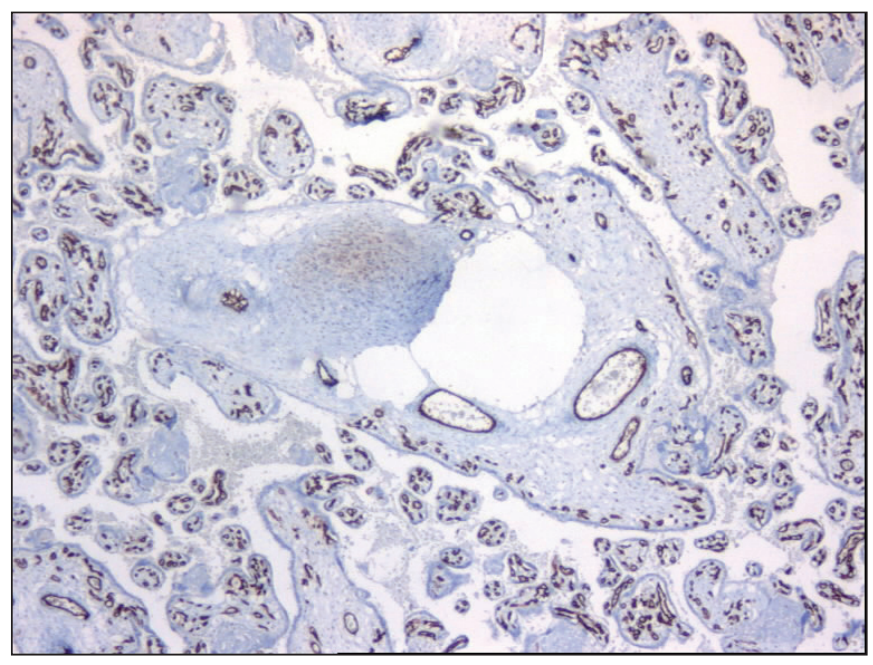

Figure 4: Villus with CD34 negative cisternae (CD34; x5). 


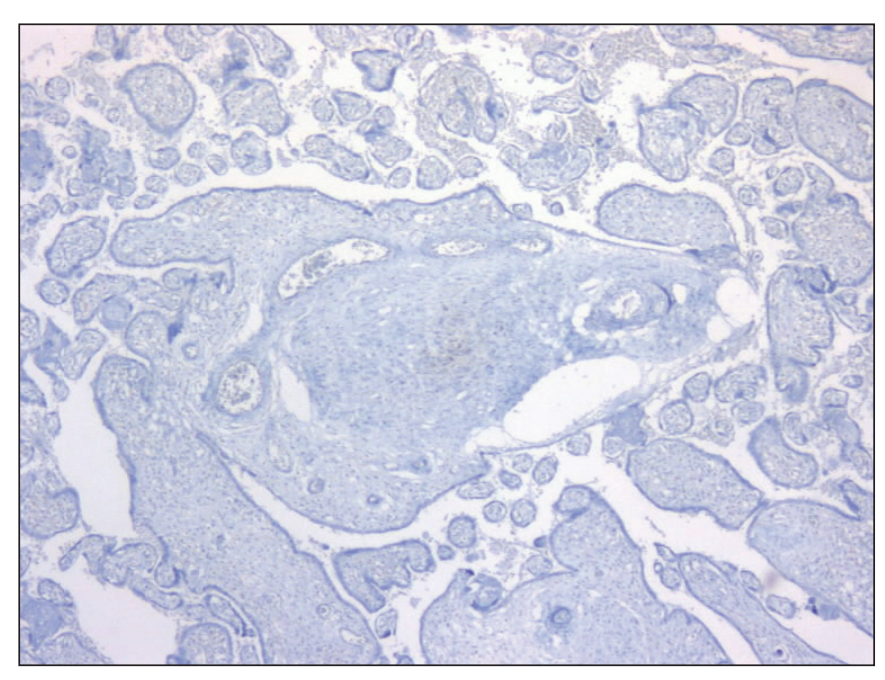

Figure 5: Villus with D2-40 negative cisternae (D2-40; x10).

\section{DISCUSSION}

Placental mesenchymal dysplasia (PMD) is a rare disorder that is estimated to occur in $0.02 \%$ of pregnancies (14). The true incidence of the PMD is difficult to calculate because it is likely to be an under-diagnosed and underreported clinico-pathological entity; and only placenta from patients with medical co-morbidities or complicated pregnancies are sent for pathological examination (13). Some pathologists are not aware of such a clinical entity $(13,15)$. The incidence of PMD may increase as a result of increasing awareness by pathologists of PMD as a clinical entity. It is therefore important to discuss the diagnostic criteria and the differential diagnosis of the disorder.

PMD is a rare benign placental anomaly that is difficult to differentiate from a complete mole with co-twin. Differential diagnosis of PMD and molar pregnancy is important because complete mole and partial mole carry significant morbidity for mother (16). On the other hand, PMD is benign disorder and termination is not needed so that only clinical follow-up is offered. PMD should be included in the differential diagnosis of sonographic findings that show a normal appearing fetus with cystic lesions of placenta (11). Detection of PMD is not only necessary for differential diagnosis of hydatidiform mole but also for clinical follow-up because it is said that PMD has a relationship with pregnancy-related hypertension (16). However, it is not known whether PMD is the result or the reason of pregnancy- related hypertension. In contrast to the literature, neither of our cases had pregnancy-related hypertension, pre-eclampsia or eclampsia. One of our cases had a cardiovascular disorder history that was associated with atrial-mitral valve impairment and resulted in valve replacement. This case had a history of hypertension but her blood pressure was under control before and during the pregnancy. Also our second case had no history of hypertension or pregnancy-related hypertension.

Neither case was diagnosed prenatally because the placental changes were not prominent enough for prenatal diagnosis but macroscopically both had an enlarged placenta with thick-walled vessels suggesting PMD. One of our cases had a chromosomal abnormality, trisomy 21 , in which hydropic villi and mild degrees of circumferential trophoblastic proliferation could be observed and this would be challenging when making the differential diagnosis of PHM $(17,18)$. To the best of our knowledge, our case is the first PMD case associated with trisomy 21. It is known that hydropic villi can be seen in trisomy $21(17,18)$ but peripherally located thick-walled vessels and the absence of trophoblastic proliferation were the most important clues for the diagnosis of PMD $(15,16)$. In both of our cases, some of the villi were hydropic and had cisternae, while some had peripherally located thick-walled vessels. These findings confirmed the diagnosis of PMD.

PMD cases have been associated with the BeckwithWiedemann Syndrome (BWS) in many cases in the literature $(14,19,20)$. The classic form of BWS includes hyperplastic visseromegaly, macroglossia, omphalocele, adrenal cytomegaly and gigantism. The association of PMD and BWS was first recognized by Lage in her series of four cases of BWS associated with placentomegaly with massive hydrops of placental stem villi and diploid DNA content (21). In PMD cases, the fetuses are usually normal but have BWS features in $25-30 \%(14,19,20)$. We did not observe any features of Beckwith-Wiedemann Syndrome in our cases.

Diagnosis of PMD is both prenatally and also histopathologically difficult. Early cases of PMD have been confused with partial hydatidiform mole (PHM) (6-10, 22). Molar pregnancies are characterized by massive fluid accumulation within the villous parenchyma that leads to formation of microcysts within the villi and trophoblastic proliferation. Fetal blood vessels are usually absent (23). PMD is an increasingly recognized abnormality that presents with placentomegaly, marked stem vessel hydrops, mesenchymal dysplasia with prominent thickwalled vessels, enlarged villi with myxoid stroma and decreased, occasionally obliterated blood vessels. Some of the surface vessels are thrombotic but the trophoblasts seem to be normal $(3,23,24)$. The most important clue for the differential diagnosis of PHM from PMD is absence of abnormal trophoblastic proliferations and trophoblastic pseudoinclusions (3). Placentomegaly, mesenchymal 
dysplasia with prominent thick-walled vessels, enlarged hydropic villi with cisternae were observed, but trophoblastic proliferations and trophoblastic pseudoinclusions were absent in our two cases.

In conclusion, PMD is an increasingly recognized placental pathology that should be differentiated from partial mole hydatidiform. Unlike molar pregnancies, PMD co-exists with viable fetuses. There is also an association with PMD and BWS. The most important message is that PMD should be considered in the differential diagnosis of a case with a normal-appearing fetus and placenta with cystic lesions. The most important point is "you can diagnose it if you consider it".

\section{REFERENCES}

1. Takayama M, Soma H, Yaguchi S, Funayama H, Fujiwara K, Irie H, Yamabe S. Abnormally large placenta associated with BeckwithWiedemann syndrome. Gynecol Obstet Invest. 1986;22:165-8.

2. Moscoso G, Jauniaux E, Hustin J. Placental vascular anomaly with diffuse mesenchymal stem villous hyperplasia. A new clinicopathological entity? Pathol Res Pract. 1991;187:324-8.

3. Surti U, Hill LM, Dunn J, Prosen T, Hoffner L. Twin pregnancy with a chimeric androgenetic and biparental placenta in one twin displaying placental mesenchymal dysplasia phenotype. Prenat Diagn. 2005;25:1048-56.

4. Zeng X, Chen MF, Bureau YA, Brown R. Placental mesenchymal dysplasia and an estimation of the population incidence. Acta Obstet Gynecol Scand. 2012;91:754-7.

5. Robertson M, Geerts LT, de Jong G, Wainwright H. Mesenchymal dysplasia in a monochorionic diamniotic twin pregnancy with review of the differential diagnosis of cystic changes in the placenta. J Ultrasound Med. 2007;26:689-93.

6. Matsui H, Iitsuka Y, Yamazawa K, Tanaka N, Mitsuhashi A, Seki $\mathrm{K}$, Sekiya S. Placental mesenchymal dysplasia initially diagnosed as partial mole. Pathol Int. 2003;53:810-3.

7. Sander CM. Angiomatous malformation of placental chorionic stem vessels and pseudo-partial molar placentas: Report of five cases. Pediatr Pathol. 1993;13:621-33.

8. Hojberg KE, Aagaard J, Henriques U, Sunde L. Placental vascular malformation with mesenchymal hyperplasia and a localized chorioangioma. A rarity simulating partial mole. Pathol Res Pract. 1994;190:808-13; discussion 14

9. Pridmore BR, Khong TY, Wells WA. Ultrasound placental cysts associated with massive placental stem villous hydrops, diploid DNA content, and exomphalos. Am J Perinatol. 1994;11:14-8.
10. Zhang P, Benirschke K. Placental pathology casebook. Serpentine aneurysms of the placenta with fetal consequences. J Perinatol. 2000;20:63-5.

11. Parveen Z, Tongson-Ignacio JE, Fraser CR, Killeen JL, Thompson KS. Placental mesenchymal dysplasia. Arch Pathol Lab Med. 2007;131:131-7.

12. Gizzo S, Di Gangi S, Patrelli TS, Saccardi C, D’Antona D, Nardelli GB. Placental mesenchymal dysplasia: Can early diagnosis ensure a good materno-foetal outcome? A case report. Arch Gynecol Obstet. 2012;286:15-7.

13. Nayeri UA, West AB, Grossetta Nardini HK, Copel JA, Sfakianaki AK. Systematic review of sonographic findings of placental mesenchymal dysplasia and subsequent pregnancy outcome. Ultrasound Obstet Gynecol. 2013;41:366-74.

14. Heazell AE, Sahasrabudhe N, Grossmith AK, Martindale EA, Bhatia K. A case of intrauterine growth restriction in association with placental mesenchymal dysplasia with abnormal placental lymphatic development. Placenta. 2009;30:654-7.

15. Gibson BR, Muir-Padilla J, Champeaux A, Suarez ES. Mesenchymal dysplasia of the placenta. Placenta. 2004;25:671-2.

16. Woo GW, Rocha FG, Gaspar-Oishi M, Bartholomew ML, Thompson KS. Placental mesenchymal dysplasia. Am J Obstet Gynecol. 2011;205:e3-5.

17. Reichert RA. Diagnostic Gynecologic and Obstetric Pathology: An Atlas and Text. Philadelphia: Lippincott Williams \& Wilkins; 2012.

18. Chew SH, Perlman EJ, Williams R, Kurman RJ, Ronnett BM. Morphology and DNA content analysis in the evaluation of first trimester placentas for partial hydatidiform mole (PHM). Human pathology. 2000;31:914-24.

19. Kaiser-Rogers KA, McFadden DE, Livasy CA, Dansereau J, Jiang R, Knops JF, Lefebvre L, Rao KW, Robinson WP. Androgenetic/ biparental mosaicism causes placental mesenchymal dysplasia. J Med Genet. 2006;43:187-92.

20. Cohen MC, Roper EC, Sebire NJ, Stanek J, Anumba DO. Placental mesenchymal dysplasia associated with fetal aneuploidy. Prenat Diagn. 2005;25:187-92.

21. Lage JM. Placentomegaly with massive hydrops of placental stem villi, diploid DNA content, and fetal omphaloceles: Possible association with Beckwith-Wiedemann syndrome. Hum Pathol. 1991;22(6):591-7.

22. Chan YF, Sampson A. Placental mesenchymal dysplasia: A report of four cases with differentiation from partial hydatidiform mole. Aust N Z J Obstet Gynaecol. 2003;43:475-9.

23. Benirschke K, Burton GJ, Baergen RN. Pathology of the Human Placenta. sixth ed. Berlin: Springer; 2012.

24. Ohyama M, Kojyo T, Gotoda H, Sato T, Ijiri R, Tanaka Y. Mesenchymal dysplasia of the placenta. Pathol Int. 2000;50:75964. 